\title{
Structural Characteristics of Lignite Char from Different Pyrolysis Reactors and the Influence on Their Gasification Reactivity
}

\author{
Ying Zhang, ${ }^{(*, a}$ Haitang Wang ${ }^{a}$ and Xiaoqin Wang ${ }^{a}$ \\ ${ }^{a}$ Shanxi Institute of Energy, 030600 Jinzhong, China
}

\begin{abstract}
The gasification reactivity of coal char is affected by numerous experimental variables, and char structure is one of the dominant factors. In this work, Raman spectroscopy, powder X-ray diffraction (XRD), and $\mathrm{N}_{2}$ adsorption were used to investigate the physical and chemical structure of char prepared under different pyrolysis conditions. Three kinds of pyrolysis reactors, fluidizedbed reactor (FL), entrained-flow-bed reactor (EF), and fixed-bed reactor (PT), were designed and used to prepare the char samples. Lignite was pyrolyzed in a fixed-bed reactor with a heating rate of $10^{\circ} \mathrm{C} \mathrm{min}{ }^{-1}$, and the final temperature was $1000^{\circ} \mathrm{C}$. The gasification reactivity of char was characterized in a quartz fixed-bed reactor under $\mathrm{CO}_{2}, \mathrm{H}_{2} \mathrm{O}$, and their mixtures at $750^{\circ} \mathrm{C}$. FB reactor produces chars with a smaller interlayer spacing of aromatic layers $\left(\mathrm{d}_{002}\right)$, and FL reactor produces chars with a larger mean crystallite size along the c-axis $\left(\mathrm{L}_{\mathrm{c}}\right)$ and aromaticity $\left(f_{\mathrm{a}}\right)$ but inhibits the growth of mean crystallite size along the a-axis $\left(\mathrm{L}_{\mathrm{a}}\right)$. The content of small aromatic rings, which is higher in the FL reactor, positively affects the initial intrinsic reactivity.
\end{abstract}

Keywords: pyrolysis reactors, char gasification, structural evolution, gasification reactivity

\section{Introduction}

Coal continues to be an essential energy source in many parts of the world, especially in China and Australia. Developing and utilizing coal resources rationally, efficiently, and environmentally is a reasonable way to alleviate the pressure of energy demand. Thus, a deeper understanding of coal structure and property becomes more important for the development of clean coal utilization. ${ }^{1,2}$ The organic structure of coal can be regarded as heterogeneous aromatic compounds, with increasing aromaticity from low rank to high rank coals..$^{3-5}$ As a low rank coal, lignite is a cheap fuel and is usually low in sulfur. On account of the over-exploitation of hard coal, more and more attention has been drawn to the exploration and utilization of lignite. The existing lignite reserves in China are about 129 billion tons, accounting for $12.9 \%$ of the total Chinese coal reserves. However, high moisture content (25-50\%) in lignite causes serious application problems, and it is generally difficult to be ground, separated, and classified. Approaches such as drying and pyrolysis are often used to upgrade lignite before the subsequent utilization process..$^{6-8}$ Nowadays, gasification has been an efficient thermal conversion process to upgrade lignite.

*e-mail: zysxnyxy@163.com

Editor handled this article: Jaísa Fernandes Soares
The gasification of coal char with low-quality lignite as raw material expands the utilization range of inferior coal. It generates synthetic gas as the main product, which invigorates the downstream capacity of the char industry chain..$^{9-12}$ In the actual industrial production process, the characteristics of coal species and the difference of process conditions will cause significant changes to the char structure and further affect the gasification efficiency. At present, studies on the correlation between chemical structure and gasification characterization of coal char, especially between coal char and gasification under $\mathrm{H}_{2} \mathrm{O}$ and $\mathrm{CO}_{2}$, are still lacking. The development and utilization of existing equipment remain an expensive and timeconsuming process, and the data provided can only be applied to a specific process. ${ }^{10,13-15}$ Therefore, it is of great significance to research coal char reactivity through the correlation between coal char structure and gasification reactivity, and finally realize the purpose of predicting the gasification reactivity of coal char based on the natural property of raw coal.

Many advanced techniques have been used to characterize the chemical and physical structures of coal char, such as Fourier transform infrared spectroscopy (FTIR), Raman spectroscopy, X-ray diffraction (XRD), $\mathrm{N}_{2}$ adsorption, and scanning electron microscope (SEM). Also, XRD has been commonly used to investigate the crystalline structure of coal char, among which some features are 
Table 1. Proximate and ultimate analysis of lignite char

\begin{tabular}{|c|c|c|c|c|c|c|c|c|}
\hline \multirow{2}{*}{ Sample } & \multicolumn{4}{|c|}{ Proximate analysis / wt. $\%$} & \multicolumn{4}{|c|}{ Ultimate analysis / wt.\% } \\
\hline & $\mathrm{M}_{\mathrm{ad}}$ & $A_{d}$ & $\mathrm{~V}_{\mathrm{daf}}$ & $\mathrm{C}_{\mathrm{daf}}$ & $\mathrm{H}_{\mathrm{daf}}$ & $\mathrm{O}^{\mathrm{a}}$ & $\mathrm{N}_{\mathrm{daf}}$ & $\mathrm{S}_{\mathrm{d}}$ \\
\hline L-1000PT & 3.29 & 13.62 & 3.47 & 96.79 & 0.55 & 1.12 & 1.14 & 0.33 \\
\hline L-1000FL & 2.21 & 11.90 & 5.84 & 92.62 & 1.36 & 4.61 & 1.04 & 0.30 \\
\hline L-1000EF & 4.18 & 14.45 & 7.31 & 93.77 & 1.50 & 3.11 & 1.16 & 0.29 \\
\hline
\end{tabular}

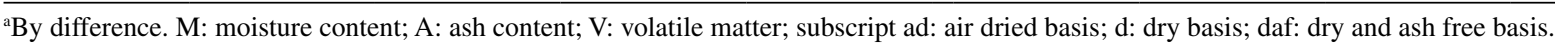

related to gasification or combustion reactivity. ${ }^{16,17}$ It has been reported that char crystallinity and highly ordered carbonaceous material negatively correlate with gasification and combustion reactivity. ${ }^{18,19}$

Some researchers used Raman spectroscopy to characterize the structural features of carbonaceous materials, including coals and chars, and D band (reflecting the disordered structure in graphite or other highly ordered carbonaceous materials) and $\mathrm{G}$ band (graphite $\mathrm{E}_{2 \mathrm{~g}}^{2}$ band) were usually assigned. ${ }^{5,20-26}$ While these two bands cannot make an accurate structural description, since there are many overlapped peaks between the D band and G band, which contain some rich information about the actual structural feature of lignite char. A series of studies on the structure of coal or coal char using Raman technique has been conducted by Li et al..$^{24-26}$ and the Raman spectra are generally deconvoluted into 10 bands to acquire detailed information about the skeletal structure of lignite char.

The gasification of coal char with $\mathrm{H}_{2} \mathrm{O}$ is a fundamental reaction in a gasifier, and $\mathrm{CO}_{2}$, which also acts as a kind of gasification agent, is one of the components in flue gas and can partially replace $\mathrm{H}_{2} \mathrm{O}$. However, the relationship between intrinsic gasification reactivity and the structural feature of lignite char in these atmospheres remains unclear. Thus, this work aims to study the structural feature of lignite char from three different reactors, fixed-bed reactor (PT), fluidized-bed reactor (FL), and entrained-flow-bed reactor $(\mathrm{EF})$, and investigate the influence on their gasification reactivity in $\mathrm{H}_{2} \mathrm{O}$ and $\mathrm{CO}_{2}$.

\section{Experimental}

\section{Sample preparation}

A Chinese lignite was used in this study, and the sample was pulverized and sieved to $96-150 \mu \mathrm{m}$. In this study, coal samples were prepared in three different pyrolysis reactors with a final pyrolysis temperature of $1000^{\circ} \mathrm{C} .10 \mathrm{~g}$ sample was put into the fixed-bed reactor and heated at $10^{\circ} \mathrm{C} \mathrm{min}^{-1}$ under $\mathrm{N}_{2}$, the flow rate of $\mathrm{N}_{2}$ was $600 \mathrm{~mL} \mathrm{~min}^{-1}(\mathrm{~L}-1000 \mathrm{PT})$. In FL and EF, the sample is heated from 25 to $1000{ }^{\circ} \mathrm{C}$ and the sampling rate was $0.2 \mathrm{~g} \mathrm{~min}^{-1}$, then held at $1000^{\circ} \mathrm{C}$ for $1 \mathrm{~h}$ with a $\mathrm{N}_{2}$ flow rate of $5000 \mathrm{~mL} \mathrm{~min}^{-1}$ in FL (L-1000FL) and $600 \mathrm{~mL} \mathrm{~min}^{-1}$ in $\mathrm{EF}$ (L-1000EF), respectively. After that, the samples in the collection bottle are cooled to room temperature under $\mathrm{N}_{2}$. The proximate and ultimate analyses of produced lignite chars (L-1000PT, L-1000FL, L-1000EF) are listed in Table 1.

\section{Char characterization}

Raman spectra of chars were recorded with a Renishaw inVia Raman spectrometer (New Mills, United Kingdom). The excitation Nd:YAG laser wavelength was $541.5 \mathrm{~nm}$; the laser power was $20 \mathrm{~mW}$. The recorded Raman spectra in the range between 800 and $1800 \mathrm{~cm}^{-1}$ were curve-fitted using Origin software ${ }^{27}$ with 10 Gaussian bands. One example of spectral deconvolution is given in Figure 1 (the detailed methodology of band assignment has been reported in references 24-26).

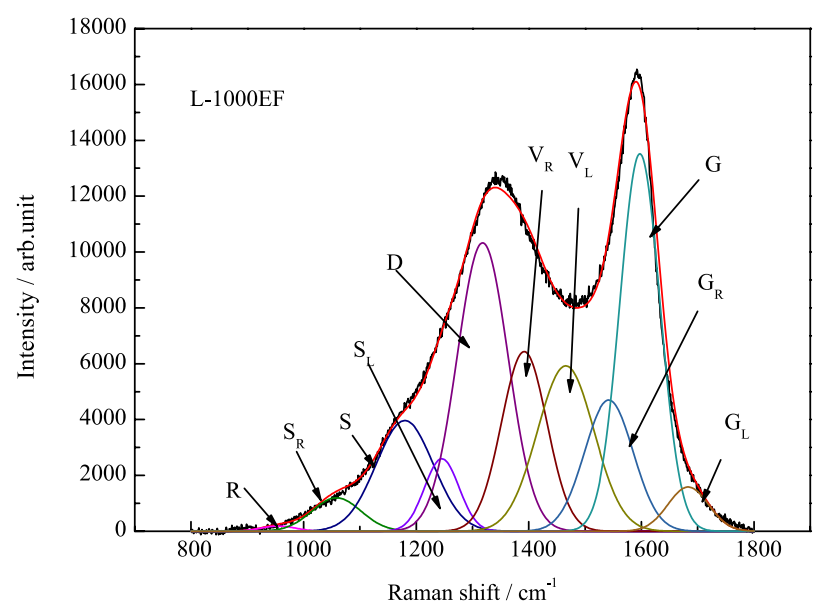

Figure 1. Curve fitting of the Raman spectrum of L-1000EF.

The carbon microcrystalline structure was characterized by the Miniflex II X-ray diffraction (XRD) instrument (Tokyo, Japan), using the $\mathrm{K} \alpha$ radiation of $\mathrm{Cu}$. The scanning

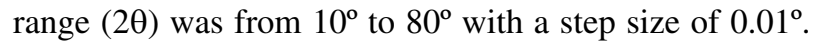
Operating conditions were: tube voltage $40 \mathrm{kV}$, tube current $100 \mathrm{~mA}$, graphite monochrome filter. Under this condition, the data of carbon microcrystalline structure was obtained 
by scanning the diffraction peak position and diffraction peak strength of the measured spectrum.

In the experiment, the low-temperature nitrogen adsorption method was used. The high purity $\mathrm{N}_{2}$ of the test gas was $-196{ }^{\circ} \mathrm{C}$, the pressure point interval was $0.1 \mathrm{KPa}$. The pore structure and surface area of the char samples were calculated using Barrett-Joyner-Halenda (BJH) and Brunauer-Emmett-Teller (BET) method.

\section{Reactivity measurements}

Reactivity measurements were conducted in a laboratory-scale fixed-bed quartz reactor at $1000^{\circ} \mathrm{C}$. The reactor suspends approximately $1.5 \mathrm{~g}$ of char on a quartz frit, into which a thermocouple is inserted to measure the temperature of the sample bed. Reactant gas $\left(30 \% \mathrm{H}_{2} \mathrm{O}+\right.$ $30 \% \mathrm{CO}_{2}+40 \% \mathrm{~N}_{2}$ ) was passed through the entire sample, and measurements of gas concentration and flow rates were used to determine reaction rates.

The carbon conversion (x) is calculated by equation 1 :

$\mathrm{x}=\frac{\mathrm{w}_{0}-\mathrm{w}}{\mathrm{w}_{0}}$

where $\mathrm{w}_{0}$ and $\mathrm{w}$ represent the initial weight (daf) and the weight (daf) of char at reaction time $t$, respectively.

The specific reaction rate $(r)$ is the as-measured reaction rate and calculated with the expression in equation 2 :

$\mathrm{r}=-\frac{1}{\mathrm{w}} \frac{\mathrm{dw}}{\mathrm{dt}}\left(\mathrm{g} \mathrm{g}^{-1} \mathrm{~s}^{-1}\right)$

The intrinsic reaction rate $\left(\mathrm{r}_{\mathrm{int}}\right)$ is the reaction rate that eliminates the effect of specific surface area and calculated by equation 3 :

$\mathrm{r}_{\text {int }}=\frac{\mathrm{r}}{\mathrm{S}}$

where $\mathrm{S}$ represents the specific surface area of char.

\section{Results and Discussion}

\section{XRD analysis}

Figure 2 shows the XRD diagram of chars pyrolyzed in $\mathrm{FL}, \mathrm{EF}$, and PT reactors at $1000^{\circ} \mathrm{C}$. It can be seen that the 002 peak of L-1000FL is much thinner and higher than that of L-1000EF and L-1000PT, and the 002 peak position of $\mathrm{L}-1000 \mathrm{FL}$ is moved to a higher degree, which indicates a better crystalline structure and a higher content of aromatic carbon. At the same time, the 100 peak of the L-1000FL is also narrower than those obtained from the other two reactors, indicating that the average size of the aromatic wafer layer in $\mathrm{L}-1000 \mathrm{FL}$ is relatively smaller.

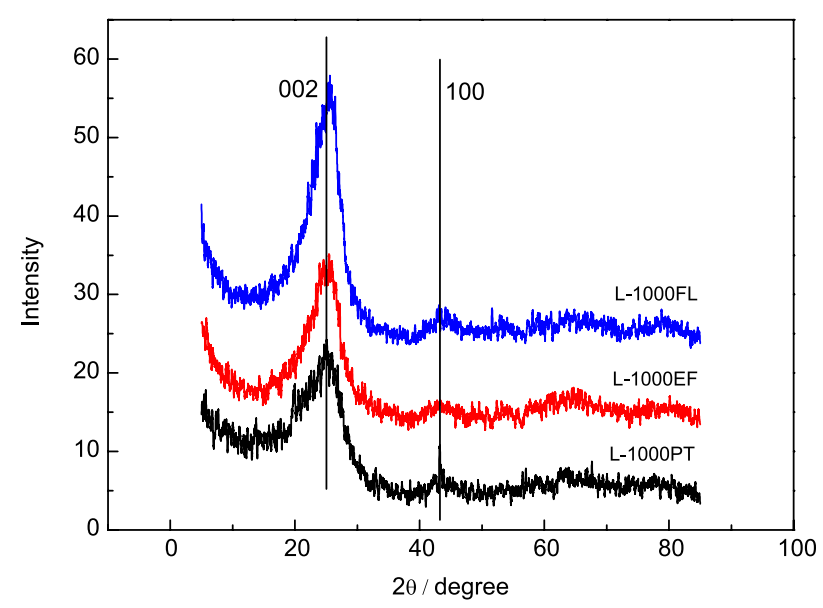

Figure 2. XRD diagram of chars from different reactors at $1000^{\circ} \mathrm{C}$.

To analyze the XRD diagram quantitatively, the 002 peak should be curve fitted. One assumption should be treated as a premise that the 002 peak and $\gamma$ peak were symmetrical peaks, and the peak position of $\gamma$ peak is far away from 002 peak without any effect on its right. ${ }^{16,17}$ An example of XRD spectral deconvolution is given in Figure 3.

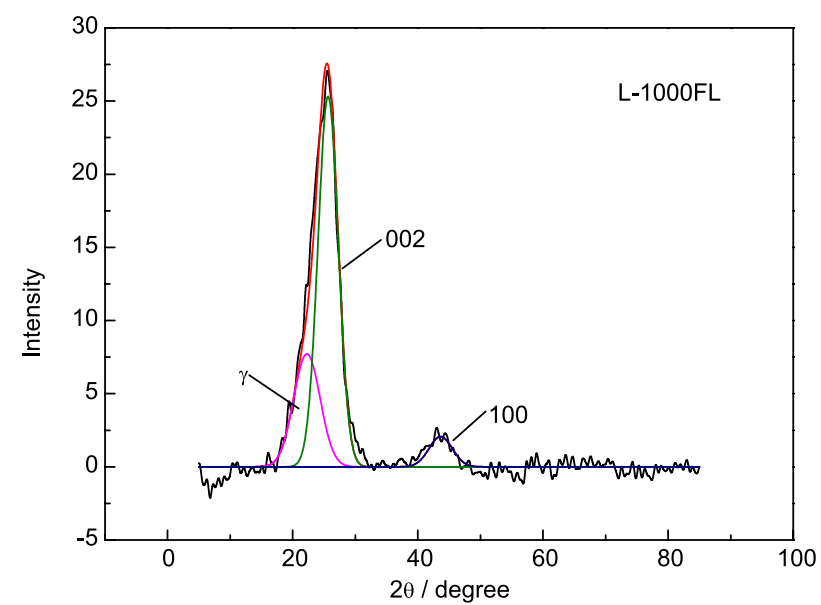

Figure 3. Curve fitting of XRD spectra of L-1000FL.

After curve fitting and calculating, the relevant data are shown in Table 2. The microcrystalline structural parameters of chars from different pyrolysis reactors are also various. The interlayer spacing of aromatic layers $\left(\mathrm{d}_{002}\right)$ of $\mathrm{L}-1000 \mathrm{FL}$ and L-1000PT seems less than L-1000EF. This could be attributed to that a longer holding time in the pyrolysis reactor contributes to a denser microcrystalline structure for lignite char. However, L-1000FL has the maximum $\mathrm{L}_{\mathrm{c}}$ 
(crystallite height) and $f_{\mathrm{a}}$ (aromaticity) value but minimum $\mathrm{L}_{\mathrm{a}}$ (crystallite diameter) value. The interactions between volatile matters and chars may positively affect the growth of mean crystallite size along the c-axis and a reverse effect on that along the a-axis.

Table 2. Microcrystalline structural parameters of chars from different reactors at $1000{ }^{\circ} \mathrm{C}$

\begin{tabular}{lcccc}
\hline Sample & $\mathrm{d}_{002} / \mathrm{nm}$ & $\mathrm{L}_{\mathrm{c}} / \mathrm{nm}$ & $\mathrm{L}_{\mathrm{a}} / \mathrm{nm}$ & $f_{\mathrm{a}}$ \\
\hline L-1000FL & 0.32 & 1.789 & 0.891 & 0.716 \\
L-1000EF & 0.373 & 1.790 & 1.199 & 0.694 \\
L-1000PT & 0.310 & 1.780 & 1.154 & 0.663 \\
\hline
\end{tabular}

$\mathrm{d}_{002}$ : interlayer spacing; $\mathrm{L}_{\mathrm{c}}$ : crystallite height; $\mathrm{L}_{\mathrm{a}}$ : crystallite diameter; $f_{\mathrm{a}}$ : aromaticity; FL: fluidized-bed reactor; EF: entrained-flow-bed reactor; PT: fixed-bed reactor.

\section{Pore structure and specific surface area analysis}

Previous works ${ }^{11,14}$ have studied the effects of different atmospheres and pressure on pore structure and specific surface area. Still, the research for the impact of reactors on pore structure and specific surface area is not sufficient. Figures 4 and 5 show the pore structure and specific surface area of chars from different pyrolysis reactors.

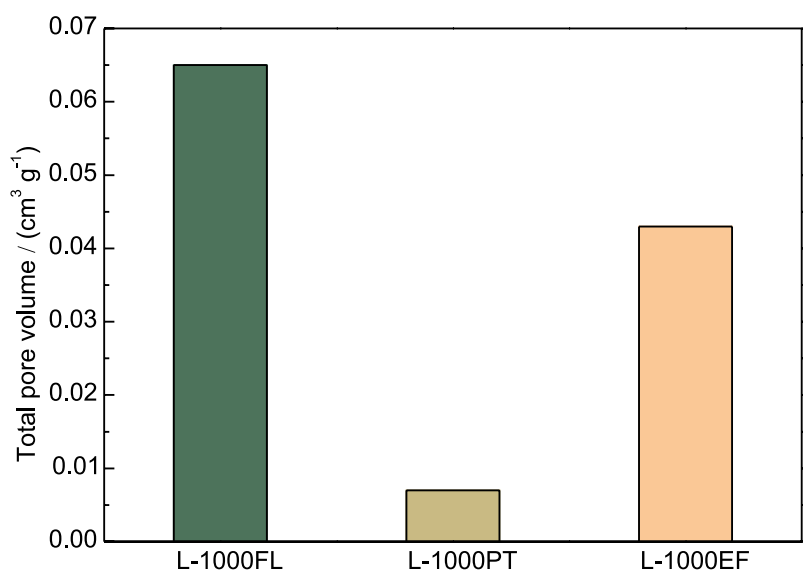

Figure 4. Effect of pyrolysis reactors on total pore volume.

The total pore volume and specific surface area of chars in FL and EF are much higher than in PT. At the same final temperature and holding time, devolatilization in FL is much more severe, and drastic devolatilization may lead to a richer pore structure and a larger specific surface area. ${ }^{28}$ The heating rate has a significant impact on the expansivity of samples, and a higher heating rate will increase the expansivity of chars. ${ }^{29}$ The heating rate in EF is much higher than that in PT which is only $10{ }^{\circ} \mathrm{C} \mathrm{min}^{-1}$, so the expansion behavior in $\mathrm{L}-1000 \mathrm{EF}$ is much more drastic than L-1000PT, resulting in a higher total pore volume and specific surface area.

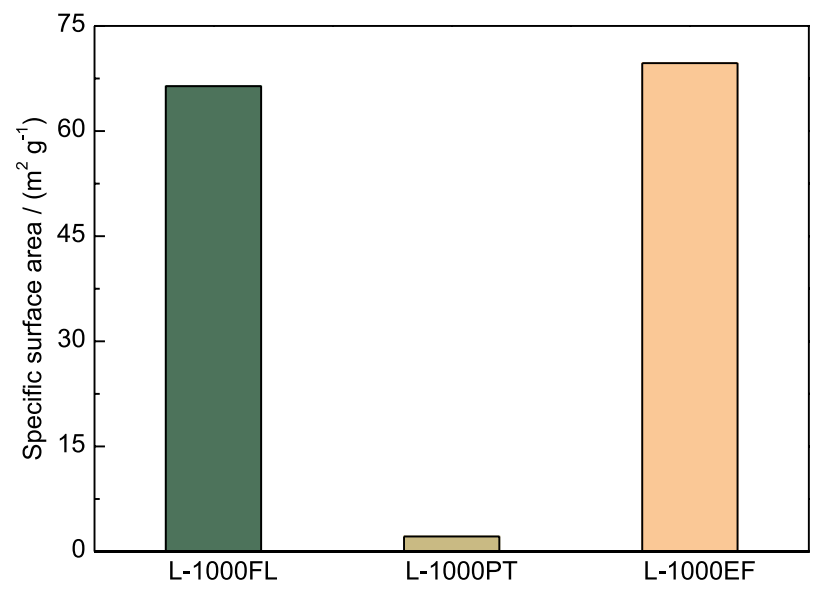

Figure 5. Effect of pyrolysis reactors on the specific surface area.

\section{Raman spectra analysis}

Raman spectra of samples were obtained to investigate the relationship between the char chemical structure and intrinsic reactivity. The spectra were deconvoluted in 10 Gaussian bands. Previous works ${ }^{12,24,26}$ show that four main factors will affect the total Raman intensity: the concentration of samples, the Raman scattering ability, the light absorptivity, and the presence of electron-rich functional groups. Figure 6 gives the result that seems to be related to the variations in the amount of electron-rich groups in different reactors. The difference of electron-rich O-containing functional groups shown in Table 1 may lead to the variation of total Raman intensity of samples.

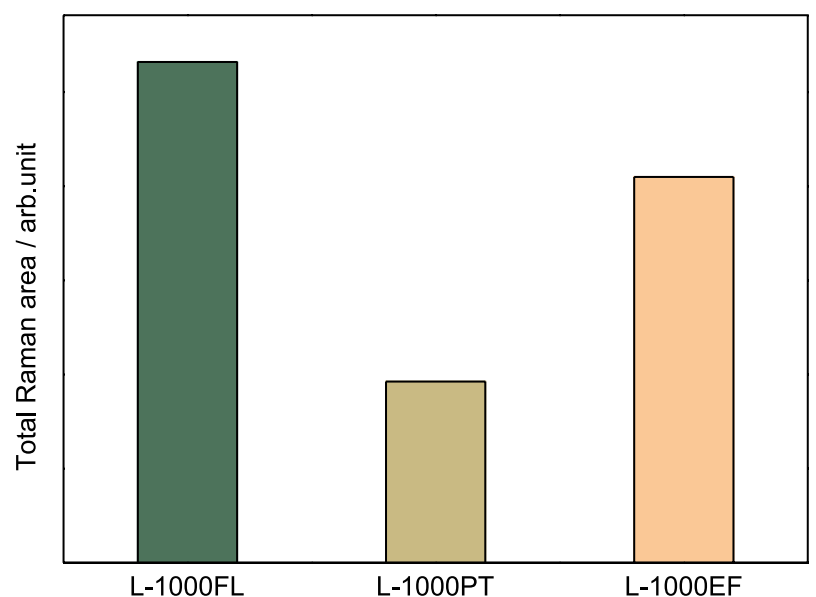

Figure 6. Raman peak areas of chars pyrolized in different reactors at $1000^{\circ} \mathrm{C}$.

Figure 7 shows the band ratios of chars from different pyrolysis reactors. The ratio of the intensity of $\mathrm{D}$ band $\left(\mathrm{I}_{\mathrm{D}}\right)$ and the intensity of $\mathrm{G}$ band $\left(\mathrm{I}_{\mathrm{G}}\right)$ is treated as an essential index to investigate the crystal and graphite-like carbon structure. The decrease of $\mathrm{I}_{\mathrm{D}} / \mathrm{I}_{\mathrm{G}}$ ratio normally presences 
an increasing extent of graphitization. The $\mathrm{S}$ band mainly represents $\mathrm{sp}^{3}$-rich structures such as alkyl-aryl $\mathrm{C}-\mathrm{C}$ structures and methyl carbon dangling to an aromatic ring. In particular, the $\mathrm{S}$ band can be considered as a brief measure of cross-linking density and substitutional groups. The ratio $\mathrm{I}_{\mathrm{D}} / \mathrm{I}_{(\mathrm{Gr}+\mathrm{Vr}+\mathrm{Vl})}$ can be taken as a brief measure of the ratio between the large aromatic ring systems ( $\geq 6$ rings) and the aromatic ring systems typically found in amorphous carbon. In Figure 7 , the ratio $I_{D} / I_{G}$ gives the information that the content of ordered structure in chars from PT reactor is higher than that from FL and EF reactors, indicating that the pyrolysis condition in PT reactor is more beneficial for graphitization of chars. The ratio $I_{S} / I_{G}$ indicates that pyrolysis conditions in EF and FL reactors produce more drastic chars' cross-linking behavior than in the PT reactor. The ratio $\mathrm{I}_{\mathrm{D}} / \mathrm{I}_{\left(\mathrm{Gr}+\mathrm{Vr}_{\mathrm{r}}+\mathrm{Vl}\right)}$ shows that a relatively moderate heating process and interaction of volatile matter in PT reactor promote the conversion of small aromatic rings ( $<6$ rings) structures to large aromatic rings ( $\geq 6$ rings) structures than that in EF and FL reactors.

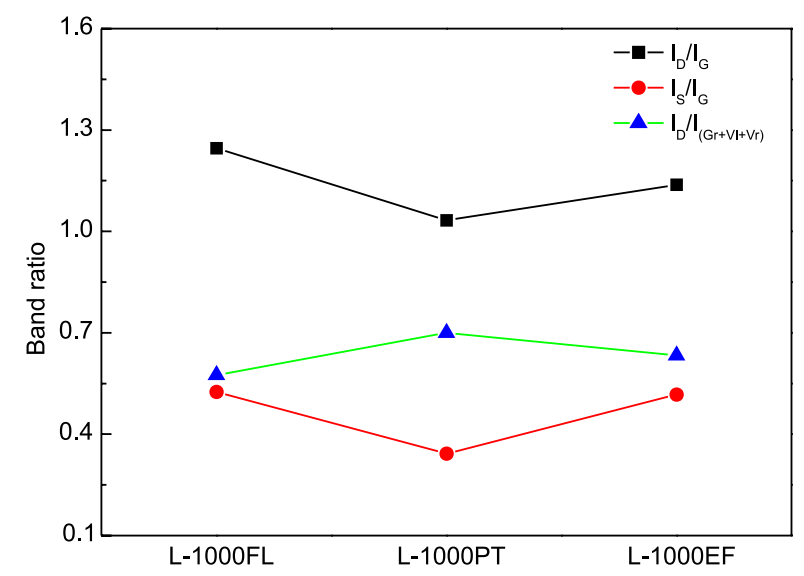

Figure 7. Band ratios as a function of chars from different reactors at $1000^{\circ} \mathrm{C}$.

\section{Char reactivity}

The intrinsic reactivity could eliminate the surface area effects associated with the specific rate and reflect the inherent features of the char surface and the influence of mineral matter and other impurities. Figure 8 shows the intrinsic reaction rate as a function of carbon conversion during reaction with $\mathrm{CO}_{2}$, steam, and their mixture at $750{ }^{\circ} \mathrm{C}$. Figure 8 indicates that the intrinsic reactivity in mixture agents is lower than that in steam but higher than that in $\mathrm{CO}_{2}$, demonstrating an interaction between $\mathrm{C}-\mathrm{CO}_{2}$ and $\mathrm{C}-\mathrm{H}_{2} \mathrm{O}$ reactions, but the mechanism is unclear.
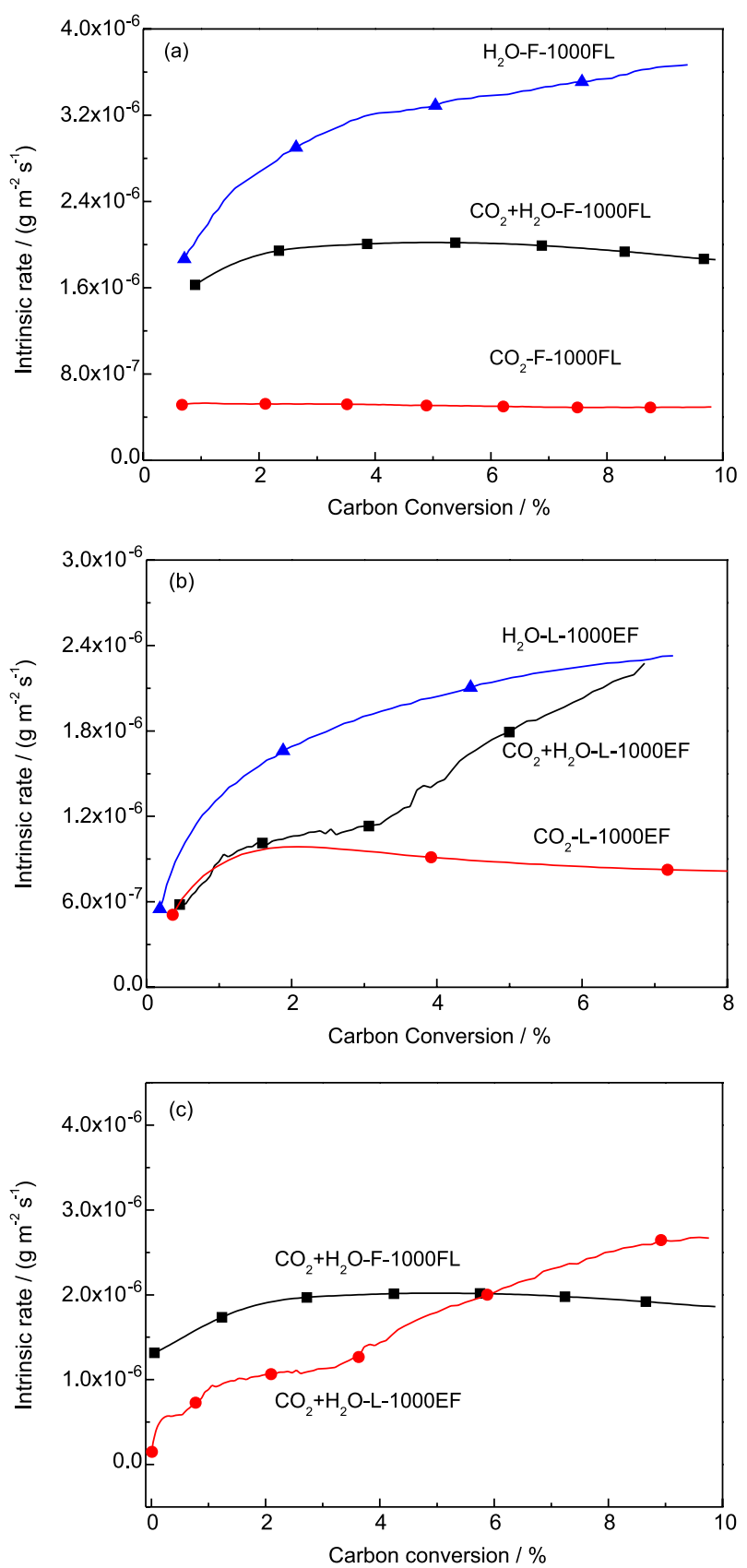

Figure 8. Comparison of the intrinsic rate of chars from FL and EF reactors with different gasification agents.

Relationships between the structure and intrinsic reactivity

The intrinsic reactivity of co-gasification has a good relationship with the structure of lignite char. The value $\mathrm{I}_{\mathrm{D}} / \mathrm{I}_{\left(\mathrm{Gr}+\mathrm{V}_{\mathrm{r}}+\mathrm{Vl}\right)}$ of L-1000FL is lower than that of L-1000EF, which reveals that there are more small aromatic rings structures in chars from FL reactor than those from EF reactor, and this difference reflects a higher initial intrinsic reactivity (conversion less than 5\%) of chars in FL reactor than that in EF reactor. After 5\% conversion, the intrinsic reactivity of L-1000EF exceeds that of L-1000FL, which 
may be caused by the changes of the content of small aromatic rings structure, but it is not clear in this research.

\section{Conclusions}

The physical and chemical structures of char samples, and intrinsic rates of lignite char gasification in $\mathrm{CO}_{2}, \mathrm{H}_{2} \mathrm{O}$ and their mixtures, were studied. Total pore volume and specific surface area were used to characterize the physical structure of chars. XRD and Raman features were used to characterize the chemical structure of chars and part of them were used to interpret relative coal char reactivity.

Pyrolysis in PT reactor produces a char with smaller interlayer spacing of aromatic layers $\left(\mathrm{d}_{002}\right)$. FL reactor produces a char with larger mean crystallite size along the c-axis $\left(\mathrm{L}_{\mathrm{c}}\right)$ and aromaticity $\left(f_{\mathrm{a}}\right)$, but inhibit the growth of mean crystallite size along the a-axis $\left(\mathrm{L}_{\mathrm{a}}\right)$. More drastic devolatilization in FL reactor produces a char that is rich in pore volume.

The intrinsic reactivity of gasification with mixtures of $\mathrm{CO}_{2}$ and steam is lower than that under steam atmosphere but higher than in $\mathrm{CO}_{2}$. The content of small aromatic rings affects the initial intrinsic reactivity, but with the conversion of chars, the change rate of small aromatic rings content may vary from chars in different pyrolysis reactors. This suggests that a study on structural changes of chars from different pyrolysis reactors versus carbon conversion is necessary, which will help get more details about the effects of reactors on char structures.

\section{Acknowledgments}

The authors gratefully acknowledge the financial support from the Shanxi Institute of Energy Project (ZY-2017005).

\section{References}

1. Chen, X.; Zheng, D.; Guo, J.; Liu, J.; Ji, P.; Energy 2013, 52, 279.

2. Baysal, M.; Yürüm, A.; Yıldız, B.; Yürüm, Y.; Int. J. Coal Geol. 2016, 163, 166.

3. Oikonomopoulos, I. K.; Perraki, M.; Tougiannidis, N.; Perraki, T.; Frey, M. J.; Antoniadis, P.; Ricken, W.; Int. J. Coal Geol. 2013, $115,1$.

4. He, X.; Liu, X.; Nie, B.; Song, D.; Fuel 2017, 206, 555.

5. Ulyanova, E. V.; Molchanov, A. N.; Prokhorov, I. Y.; Grinyov, V. G.; Int. J. Coal Geol. 2014, 121, 37.
6. Tahmasebi, A.; Yu, J.; Han, Y.; Li, X.; Fuel Process. Technol. 2012, 101, 85 .

7. Zhao, H.; Song, Q.; Liu, S.; Li, Y.; Wang, X.; Shu, X.; Energy Convers. Manage. 2018, 161, 13.

8. Zhao, H.; Li, Y.; Song, Q.; Liu, S.; Ma, L.; Shu, X.; Fuel 2021, 286, 119398.

9. Roberts, D. G.; Harris, D. J.; Fuel 2007, 86, 2672.

10. Jing, X.; Wang, Z.; Zhang, Q.; Yu, Z.; Li, C.; Huang, J.; Fang, Y.; Energy Fuels 2013, 27, 7287.

11. Tay, H. L.; Kajitani, S.; Zhang, S.; Li, C. Z.; Fuel 2013, 103, 22.

12. Wang, M.; Shen, Y.; Guo, P.; Kong, J.; Wu, Y.; Chang, L.; Wang, J.; Xie, W.; J. Anal. Appl. Pyrolysis 2020, 149, 104859.

13. Yu, J.; Guo, Q.; Ding, L.; Gong, Y.; Yu, G.; Fuel 2020, 270, 117603.

14. Wang, D.; Yang, H.; Wu, Y.; Zhao, C.; Ju, F.; Wang, X.; Zhang, S.; Chen, H.; J. Energy Inst. 2020, 93, 1999.

15. Liu, X.; Zheng, Y.; Liu, Z.; Ding, H.; Huang, X.; Zheng, C.; Fuel 2015, 157, 97.

16. Wu, S.; Gu, J.; Zhang, X.; Wu, Y.; Gao, J.; Energy Fuels 2008 , 22,199

17. Everson, R. C.; Okolo, G. N.; Neomagus, H. W. J. P.; dos Santos, J. M.; Fuel 2013, 109, 148.

18. Sonibare, O. O.; Haeger, T.; Foley, S. F.; Energy 2010, 35, 5347.

19. Liu, M.; Bai, J.; Yu, J.; Kong, L.; Bai, Z.; Li, H.; He, C.; Ge, Z.; Cao, X.; Li, W.; Energy Fuels 2020, 34, 4162.

20. Guedes, A.; Valentim, B.; Prieto, A. C.; Noronha, F.; Fuel 2012, 97, 443.

21. Hinrichs, R.; Brown, M. T.; Vasconcellos, M. A. Z.; Abrashev, M. V.; Kalkreuth, W.; Int. J. Coal Geol. 2014, 136, 52.

22. Li, K.; Khanna, R.; Zhang, J.; Barati, M.; Liu, Z.; Xu, T.; Yang, T.; Sahajwalla, V.; Energy Fuels 2015, 29, 7178.

23. Okolo, G. N.; Neomagus, H. W. J. P.; Everson, R. C.; Roberts, M. J.; Bunt, J. R.; Sakurovs, R.; Mathews, J. P.; Fuel 2015, 158, 779 .

24. Li, X.; Hayashi, J.-i.; Li, C. Z.; Fuel 2006, 85, 1700.

25. Zhang, S.; Min, Z.; Tay, H. L.; Asadullah, M.; Li, C. Z.; Fuel 2011, 90, 1529.

26. Li, T.; Zhang, L.; Dong, L.; Li, C. Z.; Fuel 2014, 117, 1190.

27. Origin, 2018b; OriginLab, Northampton, USA, 2018.

28. Li, S. F.; Wu, S. Y.; J. Fuel Chem. Technol. 2010, 38, 513.

29. Zhang, H.; Pu, W. X.; Ha, S.; Li, Y.; Sun, M.; Fuel 2009, 88, 2303.

Submitted: August 9, 2021

Published online: October 27, 2021 